\title{
SEMEADORA-ADUBADORA: EXIGÊNCIAS EM FUNÇÃO DO PREPARO DO SOLO, DA PRESSÃO DE INFLAÇÃO DO PNEU E DA VELOCIDADE ${ }^{(1)}$
}

\author{
Carlos Eduardo Angeli Furlani ${ }^{(2)}$, Rouverson Pereira da Silva ${ }^{(3)}$, Alberto Carvalho \\ Filho $^{(4)}$, Jorge Wilson Cortez ${ }^{(5)} \&$ Danilo Cesar Checchio Grotta ${ }^{(6)}$
}

\begin{abstract}
RESUMO
As semeadoras-adubadoras, responsáveis pela correta adição de semente e adubo ao solo, possuem mecanismos dosadores acionados por suas rodas motrizes, que giram em função do contato com a superfície do solo. Esse contato é influenciado, entre outros fatores, pela pressão de inflação dos pneus. O objetivo do presente trabalho foi estudar o desempenho de uma semeadora-adubadora de precisão em função do preparo do solo (preparo convencional e plantio direto), das velocidades de deslocamento e da pressão de inflação do seu pneu. $O$ trabalho foi realizado na UNESP de Jaboticabal (SP) no ano de 2006. Foram avaliadas as seguintes variáveis: força de tração e potência na barra, consumo de combustível (horário, ponderal, operacional e específico), capacidade de campo operacional, patinagem dos rodados do trator e da semeadora-adubadora, estande inicial e distribuição longitudinal de sementes. $O$ sistema plantio direto demandou maior força $(35 \%)$, potência e consumo horário de combustível; o mesmo aconteceu na maior velocidade. A pressão de inflação das rodas da semeadora proporcionou menor patinagem e maior estande inicial de plântulas.
\end{abstract}

Termos de indexação: desempenho, pressão de inflação, distribuição longitudinal.

\footnotetext{
${ }^{(1)}$ Recebido para publicação em novembro de 2006 e aprovado em outubro de 2007.

${ }^{(2)}$ Professor Adjunto do Departamento de Engenharia Rural, Universidade Estadual Paulista - UNESP/Jaboticabal. Via de Acesso Prof. Paulo Donato Castelani, km 5, Jaboticabal (SP). Bolsista de Produtividade do CNPq. E-mail: furlani@fcav.unesp.br

${ }^{(3)}$ Professor Dr., do Departamento de Engenharia Rural, UNESP/Jaboticabal. Bolsista de Produtividade do CNPq. E-mail: rouverson@fcav.unesp.br

${ }^{(4)}$ Professor Dr., Faculdades Associadas de Uberaba - FAU. Av. do Tutuna 720, Uberaba (MG). E-mail: alberto@fazu.br

(5) Mestrando em Produção Vegetal, Departamento de Engenharia Rural, UNESP/Jaboticabal. Bolsista Capes.

(6) Doutorando em Produção Vegetal, Departamento de Engenharia Rural, Unesp/Jaboticabal. Bolsista CNPq.
} 


\title{
SUMMARY: PLANTER:REQUIREMENTS AS RELATED TO SOIL TILLAGE, TIRE PRESSURE, AND MACHINE SPEED
}

\begin{abstract}
Planter machines, responsible for the correct placing of seeds and fertilizer in the ground, have dosing mechanisms set in motion by the drive wheels, as they rotate in function of the contact with the ground surface. This contact is influenced, among other factors, by tire pressure. The objective of this work was to study the performance of a planter as affected by soil tillage, machine speed and planter tire pressure. The following variables were evaluated: traction force and drawbar pull, fuel consumption, field capacity, wheel skidding, initial stand and longitudinal seed distribution. The greatest force was needed in the no-tillage system, which also demanded the highest power and hourly fuel consumption. The same results were found at the fastest speed. In this system the tire pressure of the planter wheels reduced skidding, improved the initial plant stand.
\end{abstract}

Index terms: performance, inflation pressure, longitudinal distribution.

\section{INTRODUÇÃO}

A produção de grãos em um sistema sustentável é baseada no uso de práticas conservacionistas, racionalização do uso do maquinário agrícola e sementes de qualidade. A Comissão Mundial sobre o Meio Ambiente e Desenvolvimento, citada por Barbieri (1997), define o desenvolvimento sustentável como um processo que busca satisfazer as necessidades do presente sem comprometer a possibilidade de gerações futuras atenderem às suas próprias necessidades. Assim, a operação de semeadura apresenta papel fundamental em diminuir o revolvimento do solo e manter a maior quantidade de cobertura vegetal. Nesse enfoque, existe grande desenvolvimento de semeadoras-adubadoras, porém o estudo destas em relação ao acionamento dos mecanismos dosadores deixa a desejar.

O preparo do solo tem como finalidade proporcionar condições favoráveis ao adequado desenvolvimento das culturas; contudo, a qualidade dos solos, além de influenciar as culturas, também pode auxiliar ou prejudicar o desempenho das semeadoras-adubadoras. Assim, torna-se necessário avaliar como essas máquinas trabalham em diferentes condições de solo, que seriam os sistemas de preparo (Furlani et al., 2005).

Segundo Mercante et al. (2005), a correta dosagem de semente e fertilizante pela semeadora é uma importante etapa no processo de semeadura em qualquer cultura, enquanto o processo eficiente de dosagem de sementes consiste na sua distribuição uniforme, de acordo com os padrões recomendados para a cultura.

A exigência de força em semeadoras é função de fatores como: tipo de solo, profundidade de semeadura/ adubação, velocidade de semeadura, teor de água e preparo do solo. Nesse sentido, Furlani (2005) obteve valores médios de força de tração e potência na barra, na operação de semeadura em sistema plantio direto, de $20 \mathrm{kN} \mathrm{e} 28 \mathrm{~kW}$, respectivamente, em um Latossolo
Vermelho Eutroférrico com $65 \%$ de argila. No entanto, Furlani et al. (2005) não encontraram diferenças estatísticas entre os sistemas plantio direto e preparo convencional nas variáveis: força de tração $(13,3 \mathrm{kN})$, potência $(27,3 \mathrm{~kW})$ e consumos horário $\left(14,6 \mathrm{~L} \mathrm{~h}^{-1}\right)$, operacional $\left(5,5 \mathrm{ha} \mathrm{h}^{-1}\right)$ e específico (449 $\left.\mathrm{g} \mathrm{kW} \mathrm{h}^{-1}\right)$.

Com relação à velocidade de semeadura, Cepik et al. (2005) observaram que ocorre variação da força de tração com o aumento da velocidade em um Argissolo Vermelho distrófico, na condição de umidade friável, sendo a menor força de tração $(1,3 \mathrm{kN})$ na menor velocidade $\left(4,5 \mathrm{~km} \mathrm{~h}^{-1}\right)$, na profundidade de $12 \mathrm{~cm}$. Os autores verificaram aumento da patinagem (15\%) com a maior velocidade de semeadura $\left(6,5 \mathrm{~km} \mathrm{~h}^{-1}\right)$. Nesse enfoque, Bortolotto et al. (2006) observaram diferenças significativas na força de tração na barra quando trabalharam acima de $6,5 \mathrm{~km} \mathrm{~h}^{-1}$ na operação de semeadura em um Latossolo Vermelho distrófico.

Silva et al. (2000), trabalhando em Latossolo Vermelho Eutroférrico, verificaram que a força de tração média requerida na barra de tração não sofreu variação significativa com a mudança da velocidade. $\mathrm{O}$ maior requerimento de força de tração ocorreu na maior velocidade de deslocamento, e o requerimento de força de tração por linha de semeadura foi de $2,92 \mathrm{kN}$.

A profundidade de deposição de sementes pode influenciar o requerimento de força de tração. Silveira et al. (2005), em Latossolo Vermelho distroférrico, observaram que a velocidade de deslocamento na semeadura em plantio direto provocou aumento no requerimento de força, de 12,08 e $3,70 \%$, para as profundidades $\mathrm{P} 1(1,97 \mathrm{~cm})$ e $\mathrm{P} 2(2,68 \mathrm{~cm})$, respectivamente, quando esta passou de 5,24 para $7,09 \mathrm{~km} \mathrm{~h}^{-1}$.

Seraut (1990), estudando pneus (trator) 20.8R38 com carga de $39 \mathrm{kN}$, com pressões de inflação de 80 e $160 \mathrm{kPa}$, constatou que: (a) a pressão na superfície do solo é semelhante à pressão de inflação do pneu e (b) a pressão a $30 \mathrm{~cm}$ de profundidade tem relação direta 
com a usada no pneu. McLeod et al. (1966) afirmam que a menor pressão do pneu acarreta redução da área de seção transversal do sulco de semeadura.

Somente em circunstâncias excepcionais, o solo agrícola apresenta resistência às cargas aplicadas por pneus sem exceder o limite elástico e sem deformarse permanentemente. A forma e a extensão dessas deformações dependem, sobretudo, das propriedades físicas do solo e do pneu (Maziero et al., 1997). Corrêa et al. (1999), estudando o efeito da variação de velocidade de deslocamento e diferentes pressões de inflação em superfície de concreto, observaram que o incremento da pressão de inflação do pneu gerou aumento de até $1,31 \%$ da circunferência de rolamento, pois houve aumento do raio do pneu carregado.

O aumento de velocidade de deslocamento na operação de semeadura e a variação de pressão de inflação do pneu de acionamento da semeadora-adubadora podem interferir no desempenho da máquina, principalmente trabalhando em duas condições de solo (preparo convencional e plantio direto). Assim, o objetivo do presente trabalho foi avaliar o desempenho de uma semeadora-adubadora em dois preparos do solo, em duas velocidades de deslocamento e em três pressões de inflação dos pneus.

\section{MATERIAL E MÉTODOS}

O ensaio foi realizado pelo Laboratório de Máquinas e Mecanização Agrícola (LAMMA), em área do Departamento de Engenharia Rural da UNESP/ Jaboticabal-SP, cujas coordenadas geodésicas são: latitude de $21^{\circ} 15^{\prime} \mathrm{S}$, longitude de $48^{\circ} 18^{\prime} \mathrm{W}$ e altitude de $575 \mathrm{~m}$. O clima da região é classificado como mesotérmico com inverno seco ( $\mathrm{Cwa}$ ) e com chuvas de verão, segundo classificação de Köppen. O solo da área é classificado como Latossolo Vermelho Eutroférrico típico A moderado textura argilosa (Embrapa, 1999). No momento do experimento o solo se encontrava friável.

$\mathrm{O}$ experimento foi montado em delineamento inteiramente casualizado, em esquema fatorial $2 \times 3 \times 2$ com cinco repetições, sendo dois preparos do solo (convencional e plantio direto), três pressões de inflação do pneu da semeadora $(414,483$ e $517 \mathrm{kPa})$ e duas velocidades de deslocamento $\left(3,4\right.$ e $\left.6,0 \mathrm{~km} \mathrm{~h}^{-1}\right)$.

Utilizou-se um trator Valtra BM 100 com tração dianteira auxiliar, de $76 \mathrm{~kW}$ (100 cv) de potência no motor, para operação de preparo do solo e semeadura, com as seguintes características: massa de $5.400 \mathrm{~kg}$ e $40 \%$ de lastro no eixo dianteiro [pneus 14.9-24 R1 de $3,8 \mathrm{~m}$ de perímetro e pressão de $18 \mathrm{psi}(124 \mathrm{kPa})] \mathrm{e}$ $60 \%$ de lastro no eixo traseiro [pneus 23.1-26 R1 de $4,9 \mathrm{~m}$ de perímetro e pressão de inflação de $152 \mathrm{kPa}$ (22 psi)]; arado de duas aivecas marca Maxion, trabalhando a $0,30 \mathrm{~m}$ de profundidade; grade niveladora marca Piccin de 32 discos lisos, trabalhando em média de 0,10 $\mathrm{m}$ de profundidade; semeadoraadubadora de precisão marca Marchesan (TATU) modelo PST Plus com quatro linhas de semeadura, espaçadas de $0,90 \mathrm{~m}$; e sulcador de disco duplo desencontrado para adubo no sistema convencional e haste sulcadora com ângulo de inclinação da ponteira de $20^{\circ}$ e profundidade de deposição do adubo de $11 \mathrm{~cm}$ no plantio direto. $\mathrm{O}$ pneu da semeadora foi do tipo estrada, da marca Firestone T - 615, e dimensões de 6.50-16 LT com 10 lonas, aceitando como pressão máxima 75 psi $(518 \mathrm{kPa})$.

O tempo de operação em cada parcela foi coletado por meio de um sistema de aquisição de dados, o qual dispunha de cronômetro interno com precisão de centésimos de segundos. O sistema de aquisição, acionado na entrada da parcela, armazenava os dados, que posteriormente foram descarregados por meio de um programa específico (PC 208W 3.2 - Datalogger Support Software ${ }^{\circledR}$ ) para um microcomputador via cabo. Para aquisição dos dados utilizou-se um micrologger CR23X de marca CAMPBELL SCIENTIFIC, INC ${ }^{\circledR}$. A força de tração foi obtida por meio de uma célula de carga (10 N) fabricada por M. SHIMIZU ${ }^{\circledR}$, modelo TF.

Para medir a velocidade real, utilizou-se uma unidade radar, localizada na lateral esquerda do trator, tipo RVS II. A patinagem dos rodados do trator e da semeadora foi obtida por meio de sensores de rotação ligados ao datalogger.

A capacidade de campo operacional foi determinada segundo o método proposto por Mialhe (1974), utilizando-se como eficiência de campo $75 \%$ - valor anteriormente determinado em operações de semeadura na área em estudo.

A potência $(\mathrm{kW})$ necessária no trator para tracionar a semeadora foi calculada a partir da força de tração e da velocidade de deslocamento; para medir o consumo de combustível, utilizou-se o protótipo descrito por Lopes et al. (2003), ligado automaticamente ao sistema de aquisiç̧ão de dados.

Os dados foram submetidos à análise de variância e ao teste Tukey a $5 \%$, por meio do software ESTAT 2.0 (Departamento de Ciências Exatas, UNESP/ Jaboticabal).

\section{RESULTADOS E DISCUSSÃO}

A força e a potência exigidas na barra de tração (Quadro 1) foram $53 \%$ maiores no sistema plantio direto (SPD) do que no preparo convencional. Esses valores maiores no SPD devem-se à maior resistência oferecida pelo solo aos mecanismos sulcadores da máquina. Furlani (2005) obteve valores superiores para força de tração e potência no quinto ano do SPD (20,3 kN e 28,5 kW), no mesmo tipo de solo, e umidade $5 \%$ inferior, porém utilizando semeadora de sete linhas. 
A semeadura realizada a $3,4 \mathrm{~km} \mathrm{~h}^{-1}$ apresentou menor exigência de força de tração e potência na barra, concordando com os resultados de Siqueira et al. (2001) e Mahl (2006), que também encontraram maior demanda de força de tração e potência na barra em velocidades maiores. Collins \& Fowler (1996) concluíram que houve aumento médio de $4 \%$ na demanda de força de tração para cada aumento unitário (em $\mathrm{km} \mathrm{h}^{-1}$ ) de velocidade, enquanto neste trabalho o aumento foi de $3 \%$, porém em condição de trabalho diferente. Esse aumento da força de tração e da potência pode ser devido à menor patinagem das rodas da semeadora (Quadro 1), ou seja, ocorreu menor resistência ao rolamento dos rodados da semeadora na menor velocidade. Sabendo-se que a demanda de potência é função direta da força e da velocidade, ocorreu aumento da potência com o incremento da velocidade.

As três pressões de inflação utilizadas na roda da semeadora não mostraram diferença estatística para as variáveis forças de tração, potência na barra e capacidade de campo operacional, porém ocorreu interação significativa entre os fatores preparo e pressão para as variáveis forças de tração e potência e entre os fatores preparo e velocidade para potência, como apresentado no quadro 2.
A interação preparo x pressão para a variável força de tração mostrou que foi maior no plantio direto em relação ao convencional nas três pressões (517, 483 e $414 \mathrm{kPa}$ ). A potência foi também maior no plantio direto, mas, neste sistema, as pressões de 517 e $483 \mathrm{kPa}$ exigiram menor potência em relação à menor pressão. No sistema convencional, as maiores pressões também exigiram maior potência em relação à maior pressão. Assim, pode-se aferir que as maiores pressões demandaram menor potência, o que pode ser devido à menor resistência à rolagem das rodas, como mencionado anteriormente. A interação preparo $x$ velocidade para a variável potência mostrou maior demanda para o plantio direto nas duas velocidades. A velocidade de $6,0 \mathrm{~km} \mathrm{~h}^{-1}$ também demandou maior potência, independentemente do sistema de preparo.

A capacidade de campo operacional (Quadro 1) não apresentou diferença estatística significativa para os fatores preparo e pressão. Por ser a capacidade de campo operacional função direta da velocidade de deslocamento, verificou-se que o aumento de $76,5 \%$ $\left(2,6-6,0 \mathrm{~km} \mathrm{~h}^{-1}\right)$ na velocidade proporcionou incremento de $83,3 \%$ na capacidade de campo operacional. Mahl (2006), trabalhando em solo argiloso na capacidade de campo, encontrou aumentos de $44 \mathrm{e}$

Quadro 1. Força de tração e potência na barra, capacidade de campo operacional e patinagem dos rodados do trator e da semeadora-adubadora

\begin{tabular}{|c|c|c|c|c|c|}
\hline \multirow{2}{*}{ Fator } & \multirow{2}{*}{$\begin{array}{c}\text { Força de } \\
\text { tração }\end{array}$} & \multirow{2}{*}{$\begin{array}{l}\text { Potência } \\
\text { na barra }\end{array}$} & \multirow{2}{*}{$\begin{array}{c}\text { Capacidade de } \\
\text { campo operacional }\end{array}$} & \multicolumn{2}{|c|}{ Patinagem } \\
\hline & & & & Trator & Semeadora \\
\hline Preparo (Pp) & $\mathrm{kN}$ & $\mathrm{kW}$ & ha $h^{-1}$ & 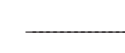 & - \\
\hline Plantio direto & $16,1 \mathrm{a}$ & $21,2 \mathrm{a}$ & $1,3 \mathrm{a}$ & $7,8 \mathrm{a}$ & $-4,4 \mathrm{~b}$ \\
\hline Convencional & $10,5 \mathrm{~b}$ & $13,8 \mathrm{~b}$ & $1,3 \mathrm{a}$ & $4,0 \mathrm{~b}$ & $-7,0 \mathrm{a}$ \\
\hline \multicolumn{6}{|l|}{ Pressão (Ps) } \\
\hline $517 \mathrm{kPa}$ & $12,8 \mathrm{a}$ & $16,8 \mathrm{a}$ & $1,3 \mathrm{a}$ & $6,5 \mathrm{a}$ & $-3,6 \mathrm{~b}$ \\
\hline $483 \mathrm{kPa}$ & $13,6 \mathrm{a}$ & $17,8 \mathrm{a}$ & $1,3 \mathrm{a}$ & 5,6 a & $-7,1$ a \\
\hline $414 \mathrm{kPa}$ & $13,5 \mathrm{a}$ & $17,9 \mathrm{a}$ & $1,3 \mathrm{a}$ & $5,5 \mathrm{a}$ & $-6,5 \mathrm{a}$ \\
\hline \multicolumn{6}{|l|}{ Velocidade (V) } \\
\hline $3,4 \mathrm{~km} \mathrm{~h}^{-1}$ & $12,8 \mathrm{~b}$ & $11,9 \mathrm{~b}$ & $0,9 \mathrm{~b}$ & $5,6 \mathrm{a}$ & $-4,1 \mathrm{~b}$ \\
\hline $6,0 \mathrm{~km} \mathrm{~h}^{-1}$ & 13,8 a & 23,1 a & $1,7 \mathrm{a}$ & $6,1 \mathrm{a}$ & $-7,2 \mathrm{a}$ \\
\hline \multicolumn{6}{|l|}{ Teste F } \\
\hline Preparo & $395,8 *$ & $349,3 *$ & $0,7 \mathrm{~ns}$ & $20,1 *$ & $5,7 *$ \\
\hline Pressão & $2,7 \mathrm{~ns}$ & $3,2 \mathrm{~ns}$ & $0,7 \mathrm{~ns}$ & $0,6 \mathrm{~ns}$ & $4,0 *$ \\
\hline Velocidade & $10,5 *$ & 805,4 * & $1.658,1^{*}$ & $0,4 \mathrm{~ns}$ & $7,7 *$ \\
\hline $\mathrm{Pp} \times \mathrm{Ps}_{\mathrm{s}}$ & $3,9 *$ & $7,4 *$ & $0,58 \mathrm{~ns}$ & $1,9 \mathrm{~ns}$ & $0,1 \mathrm{~ns}$ \\
\hline $\mathrm{Pp} \times \mathrm{V}$ & $2,4 \mathrm{~ns}$ & $46,0 *$ & $0,01 \mathrm{~ns}$ & $2,7 \mathrm{~ns}$ & $8,7 *$ \\
\hline Ps $x$ V & $0,01 \mathrm{~ns}$ & $0,78 \mathrm{~ns}$ & $0,7 \mathrm{~ns}$ & $1,4 \mathrm{~ns}$ & $0,1 \mathrm{~ns}$ \\
\hline$P p \times P s \times V$ & $0,09 \mathrm{~ns}$ & $0,24 \mathrm{~ns}$ & $0,8 \mathrm{~ns}$ & $0,8 \mathrm{~ns}$ & $0,1 \mathrm{~ns}$ \\
\hline Média & 13,3 & 17,5 & 1,3 & 5,9 & 5,7 \\
\hline CV (\%) & 7,4 & 7,7 & 4,8 & 49,8 & 65,3 \\
\hline
\end{tabular}

*,** e ns: Significativos a 5, $1 \%$ e não-significativo, respectivamente. 
Quadro 2. Interação entre os fatores preparo e pressão para as variáveis forças de tração e potência e entre preparo e velocidade para a variável potência

\begin{tabular}{|c|c|c|c|}
\hline \multirow[t]{2}{*}{ Preparo } & \multicolumn{3}{|c|}{$\begin{array}{c}\text { Força de tração }(\mathrm{kN}) \\
\text { Pressão de inflação }(\mathrm{kPa})\end{array}$} \\
\hline & 517 & 483 & 414 \\
\hline Plantio direto & 15,6 a $\mathrm{A}$ & 16,0 a $\mathrm{A}$ & 15,6 a $\mathrm{A}$ \\
\hline \multirow[t]{3}{*}{ Convencional } & $10,1 \mathrm{~b} \mathrm{~A}$ & $11,2 \mathrm{~b} \mathrm{~A}$ & $10,1 \mathrm{~b} \mathrm{~A}$ \\
\hline & \multicolumn{3}{|c|}{ Pressão (kPa) } \\
\hline & 517 & 483 & 414 \\
\hline Plantio direto & 20,9 a B & 20,4 a B & 22,2 a $\mathrm{A}$ \\
\hline \multirow[t]{4}{*}{ Convencional } & $12,7 \mathrm{~b} \mathrm{~B}$ & $13,6 \mathrm{~b} \mathrm{~B}$ & $15,2 \mathrm{~b} \mathrm{~A}$ \\
\hline & \multicolumn{3}{|c|}{ Potência (kW) } \\
\hline & \multicolumn{3}{|c|}{ Velocidade $\left(\mathrm{km} \mathrm{h}^{-1}\right)$} \\
\hline & 3,4 & & 6,0 \\
\hline Plantio direto & 14,3 a B & & 28,0 a $\mathrm{A}$ \\
\hline Convencional & $9, \mathrm{~b} \mathrm{~B}$ & & $18,1 \mathrm{~b} \mathrm{~A}$ \\
\hline
\end{tabular}

Médias seguidas de mesma letra, minúscula nas colunas e maiúscula nas linhas, não diferem entre si pelo teste de Tukey a $5 \%$.

$84 \%$ na capacidade de campo operacional, com incrementos de 2,4 e $2,2 \mathrm{~km} \mathrm{~h}^{-1}$, respectivamente; Justino (1998) também obteve aumento semelhante no mesmo tipo de solo.

A patinagem dos rodados do trator foi maior no sistema plantio direto, porém não afetou significativamente a velocidade de deslocamento. A patinagem no plantio direto foi próxima dos valores estabelecidos por Mialhe (1996) como faixa ótima (7-10 \%). Na análise dos valores de patinagem foram encontrados altos índices de coeficiente de variação, porém ainda inferiores a alguns encontrados na literatura, como os de Mahl (2002), Mahl et al. (2005) e Mahl (2006).

As pressões de inflação dos pneus da semeadora não influenciaram a patinagem dos rodados do trator. O mesmo ocorreu nas duas velocidades de deslocamento do conjunto. Em estudos realizados em solo argiloso, Mahl (2006) encontrou aumento de $16,6 \%$ na patinagem quando do incremento da velocidade de 5,5 para $10,1 \mathrm{~km} \mathrm{~h}^{-1}$; resultados semelhantes também foram encontrados por Mahl et al. (2005).

As rodas acionadoras dos mecanismos dosadores da semeadora-adubadora apresentam patinagem negativa, ou seja, são arrastadas em função do deslocamento do trator. Pode-se observar no quadro 1 que, no plantio direto, o arraste da roda foi menor.
No sistema convencional, o solo está mais mobilizado e, portanto, pode ter ocorrido maior resistência ao rolamento e, conseqüentemente, maior arraste. A maior pressão de inflação dos pneus da semeadoraadubadora proporcionou menor patinagem (arraste).

Apesar de não ter ocorrido diferença estatística para a força de tração e potência em função da pressão (Quadro 1), observa-se que, nas menores pressões, elas foram maiores numericamente, o que indica o maior arraste das rodas da semeadora nas menores pressões, nas quais, teoricamente, os pneus apresentavam maior área de contato com o solo. O ideal seria a menor patinagem possível, pois esta influencia diretamente a distribuição de sementes. A maior velocidade também apresentou maior patinagem, o que pode ser explicado pelo fato de as rodas serem arrastadas, e, com o aumento da velocidade, a possibilidade de giro da roda é menor. Mahl (2006) observou que o aumento de velocidade não interferiu no deslizamento das rodas da semeadora em sistema plantio direto; no entanto, Justino (1998) encontrou menores valores de deslizamento nas maiores velocidades em semeadura direta de milho. A patinagem dos rodados da semeadora apresentou interação significativa entre os fatores preparo e velocidade, como apresentado no quadro 3.

A interação entre os fatores preparo e velocidade na variável patinagem mostrou que, na maior velocidade, ocorreu maior arraste das rodas no preparo convencional - mais que o dobro em relação ao plantio direto. Analisando somente o preparo convencional, nota-se também aumento significativo quando do incremento da velocidade, mais de $250 \%$, provavelmente devido à maior resistência ao rolamento, efeito esse já mencionado anteriormente. No plantio direto, a patinagem não apresentou diferença significativa.

No quadro 4 são apresentados os consumos de combustível na operação de semeadura.

O consumo horário de combustível foi maior no plantio direto, fato esse relacionado à maior demanda de força de tração e potência exigidas nesse sistema.

\section{Quadro 3. Interação entre os fatores preparo e velocidade para a variável patinagem nos rodados da semeadora

\begin{tabular}{ccc}
\hline Preparo & \multicolumn{2}{c}{$\begin{array}{c}\text { Patinagem (\%) } \\
\text { Velocidade }\left(\mathbf{k m ~ h}^{-1}\right)\end{array}$} \\
\cline { 2 - 2 } & \multicolumn{3}{c}{$\mathbf{3 , 4}$} \\
\hline Plantio direto & 4,5 a A & 4,3 b A \\
Convencional & 3,9 a B & 10,1 a A \\
\hline
\end{tabular}

Médias seguidas de mesma letra, minúscula nas colunas e maiúscula nas linhas, não diferem entre si pelo teste de Tukey a $5 \%$. 
Quadro 4. Consumo de combustível horário, operacional, por massa e específico na operação de semeadura

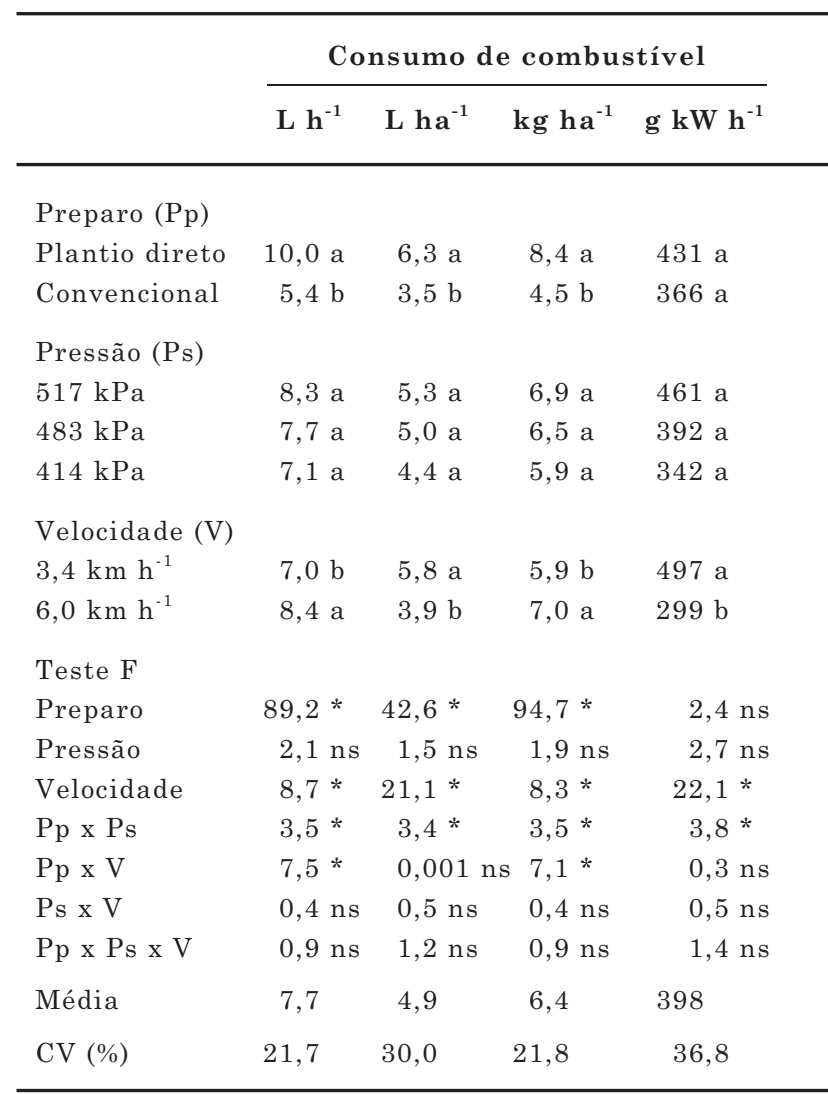

*, ** e ns: Significativos a 5, $1 \%$ e não-significativo, respectivamente.

A força de tração e a potência aumentaram $53 \%$, enquanto o consumo horário aumentou $185 \%$. A pressão de inflação dos pneus não influenciou essa variável; já o aumento de velocidade, que proporcionou aumento da potência, aumentou o consumo em $20 \%$, ou seja, $7,7 \%$ a cada $1 \mathrm{~km} \mathrm{~h}^{-1}$. Esse efeito de aumento do combustível em função da velocidade também foi observado por Oliveira (1997) e Mahl (2002). O consumo horário de combustível mostrou interação significativa entre preparo e pressão e preparo e velocidade (Quadro 5).

O consumo horário de combustível foi maior no plantio direto nas três pressões de inflação. Entretanto, analisando isoladamente o sistema de preparo, observa-se que no plantio direto o aumento de pressão não interferiu no consumo, enquanto no preparo convencional o aumento de 414 para $517 \mathrm{kPa}$ gerou aumento no consumo. Houve aumento do consumo com a velocidade no plantio direto, o que não ocorreu no convencional, podendo isso ser explicado pela maior exigência de potência no plantio direto. No preparo convencional, devido ao solo ter sido mobilizado, houve menor resistência e, conseqüentemente, menor consumo de combustível.
O consumo operacional de combustível, para os fatores preparo do solo e pressão dos pneus, apresentou o mesmo comportamento que o consumo horário. Entretanto, o consumo horário operacional foi influenciado pela velocidade, sendo o menor consumo na maior velocidade. $\mathrm{O}$ aumento da velocidade proporcionou aumento de $83 \%$ na capacidade de campo operacional e diminuição de $32 \%$ no consumo operacional. Mahl et al. (2005) também encontraram redução significativa do consumo operacional em função do aumento de velocidade. A interação preparo e pressão para a variável consumo operacional mostrou aumento no consumo para o plantio direto nas menores pressões, em relação ao convencional. Também

Quadro 5. Interação entre os fatores para as variáveis consumo horário de combustível, consumo operacional, consumo operacional em massa e consumo específico

\begin{tabular}{|c|c|c|c|}
\hline \multirow{2}{*}{ Preparo } & \multicolumn{3}{|c|}{$\begin{array}{c}\text { Consumo horário }\left(\mathrm{L} \mathrm{h}^{-1}\right) \\
\text { Pressão }(\mathrm{kPa})\end{array}$} \\
\hline & 517 & 483 & 414 \\
\hline Plantio direto & 9,7 a $\mathrm{A}$ & 10,3 a $\mathrm{A}$ & 10,0 a $\mathrm{A}$ \\
\hline \multirow[t]{3}{*}{ Convencional } & $6,9 \mathrm{~b} \mathrm{~A}$ & $5,2 \mathrm{~b} \mathrm{AB}$ & $4,2 \mathrm{~b} \mathrm{~B}$ \\
\hline & \multicolumn{3}{|c|}{$\begin{array}{c}\text { Consumo horário }\left(\mathrm{L} \mathrm{h}^{-1}\right) \\
\text { Velocidade }\left(\mathrm{km} \mathrm{h}^{-1}\right)\end{array}$} \\
\hline & 3,4 & & 6,0 \\
\hline Plantio direto & 8,6 a $\mathrm{B}$ & & 11,4 a $\mathrm{A}$ \\
\hline Convencional & $5,4 \mathrm{~b} \mathrm{~A}$ & & $5,5 \mathrm{~b} \mathrm{~A}$ \\
\hline
\end{tabular}

Consumo operacional $\left(\mathrm{L} \mathrm{ha}^{-1}\right)$

\begin{tabular}{ccc}
\multicolumn{3}{c}{ Pressão (kPa) } \\
\hline $\mathbf{5 1 7}$ & $\mathbf{4 8 3}$ & $\mathbf{4 1 4}$ \\
5,9 a A & 6,8 a A & 6,1 a A \\
4,7 a A & 3,2 b AB & 2,6 b B
\end{tabular}

Consumo operacional $\left(\mathrm{kg} \mathrm{ha}^{-1}\right)$

\begin{tabular}{lr}
\multicolumn{2}{c}{ Velocidade $\left(\mathbf{k m ~ h}^{-\mathbf{1}}\right)$} \\
\hline $\mathbf{3 , 4}$ & $\mathbf{6 , 0}$ \\
7,3 a B & 9,6 a A \\
4,4 b A & 4,5 b A
\end{tabular}

Consumo específico $\left(\mathrm{g} \mathrm{kW} \mathrm{h}^{-1}\right)$

\begin{tabular}{ccc}
\multicolumn{3}{c}{ Pressão (kPa) } \\
\hline 517 & 483 & 414
\end{tabular}

Plantio direto $\quad 412$ a A $\quad 477$ a A 402 a A

Convencional $\quad 510$ a A $\quad 305$ b B 282 a B

Médias seguidas de mesma letra, minúscula nas colunas e maiúscula nas linhas, não diferem entre si pelo teste de Tukey a $5 \%$. 
ocorreu diminuição do consumo no preparo convencional da maior para a menor pressão.

A análise do consumo operacional de combustível em massa (Quadros 4 e 5) mostrou comportamento semelhante ao do consumo horário. O consumo específico de combustível foi maior na menor velocidade, fato explicado pela menor potência demandada na barra de tração. Analisando-se a interação no plantio direto, o consumo específico não mostrou diferença estatística, porém, no preparo convencional, as menores pressões de inflação apresentaram menor consumo específico, pelo mesmo motivo explicado anteriormente.

O estande inicial de plantas foi influenciado pela pressão de inflação das rodas da semeadora (Quadro 6), sendo maior na maior pressão, o que é explicado pelo fato de que nas menores pressões 0 arraste das rodas (patinagem) foi maior (Quadro 1). Essa variável não foi influenciada pelo preparo do solo e pela velocidade de deslocamento.

A ocorrência de espaçamentos falhos e duplos seria desejável valor nulo para ambos, porém, em função de diversos parâmetros da máquina e do solo isso não ocorre, os valores encontrados para esses espaçamentos são considerados baixos por Casão Júnior et al. (2001), e não apresentaram diferença estatística para nenhum dos três fatores. O espaçamento aceitável ficou acima de $80 \%$ e não diferiu estatisticamente para os fatores preparo, pressão e velocidade. Esses valores estão de acordo com Coelho (1996), porém, os valores de coeficiente de variação são superiores aos admitidos por este autor.

\section{CONCLUSÕES}

1. A força e a potência na barra de tração e o consumo de combustível horário e operacional foram maiores no sistema plantio direto na velocidade maior, mas não foram influenciados pela pressão de inflação do pneu da semeadora.

2. O sistema plantio direto ofereceu maior patinagem ao trator. Nas rodas da semeadora, a maior patinagem aconteceu no preparo convencional. A maior pressão das rodas da semeadora diminuiu sua patinagem, influenciando diretamente a obtenção de maior estande inicial.

3. Os consumos de combustível operacional e específico foram maiores nas menores velocidades. $80 \%$.

4. Os espaçamentos aceitáveis foram superiores a

Quadro 6. Variáveis agronômicas na operação de semeadura da cultura do milho

\begin{tabular}{|c|c|c|c|c|}
\hline & \multirow{2}{*}{ Estande inicial } & \multicolumn{3}{|c|}{ Espaçamento } \\
\hline & & Falhos & Duplos & Aceitáveis \\
\hline Preparo (Pp) & plantas $\mathrm{ha}^{-1}$ & 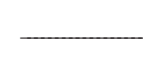 & - $\%$ & + \\
\hline Plantio direto & $84.259 \mathrm{a}$ & $7,7 \mathrm{a}$ & $4,0 \mathrm{a}$ & 88,3 a \\
\hline Convencional & $83.565 \mathrm{a}$ & $7,8 \mathrm{a}$ & $6,5 \mathrm{a}$ & 85,7 a \\
\hline \multicolumn{5}{|l|}{ Pressão (Ps) } \\
\hline $517 \mathrm{kPa}$ & $86.458 \mathrm{a}$ & $8,2 \mathrm{a}$ & $3,5 \mathrm{a}$ & 88,3 a \\
\hline $483 \mathrm{kPa}$ & $81.069 \mathrm{~b}$ & $7,0 \mathrm{a}$ & $7,4 \mathrm{a}$ & 85,6 a \\
\hline $414 \mathrm{kPa}$ & $80.208 \mathrm{~b}$ & $8,1 \mathrm{a}$ & $4,9 \mathrm{a}$ & $87,0 \mathrm{a}$ \\
\hline \multicolumn{5}{|l|}{ Velocidade (V) } \\
\hline $3,4 \mathrm{~km} \mathrm{~h}^{-1}$ & $84.722 \mathrm{a}$ & $6,1 \mathrm{a}$ & $4,8 \mathrm{a}$ & $89,2 \mathrm{a}$ \\
\hline $6,0 \mathrm{~km} \mathrm{~h}^{-1}$ & $83.102 \mathrm{a}$ & 9,4 a & 5,7 a & 84,9 a \\
\hline \multicolumn{5}{|l|}{ Teste F } \\
\hline Preparo & $0,2 \mathrm{~ns}$ & $0,01 \mathrm{~ns}$ & $2,48 \mathrm{~ns}$ & $1,26 \mathrm{~ns}$ \\
\hline Pressão & $5,5 *$ & $0,17 \mathrm{~ns}$ & $2,1 \mathrm{~ns}$ & $0,39 \mathrm{~ns}$ \\
\hline Velocidade & $1,0 \mathrm{~ns}$ & $3,19 \mathrm{~ns}$ & $0,35 \mathrm{~ns}$ & $3,37 \mathrm{~ns}$ \\
\hline $\mathrm{Pp} \times \mathrm{Ps}_{\mathrm{s}}$ & $0,8 \mathrm{~ns}$ & $1,35 \mathrm{~ns}$ & $0,72 \mathrm{~ns}$ & $0,56 \mathrm{~ns}$ \\
\hline Pp x V & $0,2 \mathrm{~ns}$ & $2,41 \mathrm{~ns}$ & $2,12 \mathrm{~ns}$ & $0,37 \mathrm{~ns}$ \\
\hline Ps $x$ V & $0,2 \mathrm{~ns}$ & $1,21 \mathrm{~ns}$ & $0,44 \mathrm{~ns}$ & $0,62 \mathrm{~ns}$ \\
\hline$P p \times P s \times V$ & $0,2 \mathrm{~ns}$ & $1,0 \mathrm{~ns}$ & $2,15 \mathrm{~ns}$ & $1,77 \mathrm{~ns}$ \\
\hline Média & 83.912 & 7,8 & 5,3 & 87,0 \\
\hline
\end{tabular}

*, ** e ns: Significativos a 5, $1 \%$ e não-significativo, respectivamente. 


\section{AGRADECIMENTOS}

Os autores agradecem à Fundação de Amparo à Pesquisa do Estado de São Paulo (Fapesp) e à Valtra do Brasil.

\section{LITERATURA CITADA}

BARBIERI, J.C. Desenvolvimento e meio ambiente: As estratégias de mudanças da agenda 21. Petrópolis, Vozes, 1997. p.23-45.

BORTOLOTTO, V.C.; PINHEIRO NETO, R. \& BORTOLOTTO, M.C. Demanda energética de uma semeadora-adubadora para soja sob diferentes velocidades de deslocamento e coberturas do solo. Eng. Agríc., 26:122-130, 2006.

CASÃO JÚNIOR, R.; SIQUEIRA, R. \& ARAÚJO, A.G. Dinâmica de semeadoras adubadoras de plantio direto (Parte II). Plantio Direto, 65:21-27, 2001.

CEPIK, C.T.C.; TREIN, C.R. \& LEVIEN, R. Força de tração e volume de solo mobilizado por haste sulcadora em semeadura direta sobre campo nativo, em função do teor de água no solo, profundidade e velocidade de operação. Eng. Agríc., 25:447-457, 2005.

COELHO, J.L.D. Ensaio \& certificação das máquinas para a semeadura. In: MIALHE, L.G., ed. Máquinas agrícolas. Piracicaba, FEALQ, 1996. p.551-570.

COLLINS, B.A. \& FOWLER, D.B. Effect of soil characteristics, seeding depth, operating speed, and opener design on draft force during direct seeding. Soil Till. Res., 39:199$211,1996$.

CORRÊA, I.M.; YANAI, K.; MAZIERO, J.V.G. \& LANÇAS, K.P. Determinação da circunferência de rolamento de pneus agrícolas utilizando dois métodos: Manual e eletrônico. Bragantia, 58:179-184, 1999.

EMPRESA BRASILEIRA DE PESQUISA AGROPECUÁRIA EMBRAPA. Sistema brasileiro de classificação de solos. Brasília, 1999. 412p.

FURLANI, C.E.A. Sistemas de manejo e rotação de culturas de cobertura em plantio direto de soja e milho. Jaboticabal, Universidade Estadual Paulista, 2005.99p. (Tese de Livre Docência)

FURLANI, C.E.A.; SILVA, R.P. \& LOPES, A. Avaliação de semeadora-adubadora de precisão trabalhando em três sistemas de preparo do solo. Eng. Agríc., 25:458-464, 2005.

JUSTINO, A. Desempenho de disco dosador de disco perfurado horizontal na distribuição de sementes de milho (Zea mays L.), em sistema de plantio direto. Botucatu, Universidade Estadual Paulista, 1998. 140p. (Tese de Doutorado)

LOPES, A.; FURLANI, C.E.A. \& SILVA, R.P. Desenvolvimento de um protótipo para medição do consumo de combustível em tratores. R. Bras. Agroinfor., 5:24-31, 2003.
MAHL, D. Desempenho de semeadoras-adubadoras de milho (Zea mays L.) em sistema de plantio direto. Botucatu, Universidade Estadual Paulista, 2002. 160p. (Tese de Mestrado)

MAHL, D. Desempenho operacional de semeadora em função de mecanismos de corte, velocidade e solos, no sistema de plantio direto do milho. Botucatu, Universidade Estadual Paulista, 2006. 143p. (Tese de Doutorado)

MAHL, D.; SANTOS, F.A.; YANO, E.H.; SILVA, P.R.A. \& GAMERO, C.A. Influência do aumento da velocidade na operação de semeadura da cultura do tremoço em sistema plantio direto. In: CONGRESO ARGENTINO DE INGENIERÍA RURAL, 8., Villa de Merlo, 2005. Anais. San Luiz, 2005. CD-ROM.

MAZIERO, J.V.G.; MIALHE, L.G.; CORREA, I.M.; YANAI, K. \& MENEZES, J.F. Efeito da patinagem da roda motriz de um trator agrícola na compactação do solo. Bragantia, 56:191-197, 1997.

McLEOD, H.E.; REED, I.F.; JOHNSON, W.H. \& GILL, W.R. Draft, power efficiency, and soil-compaction characteristics of single, dual and low-pressure tires. Trans. Am. Soc. Agron. Eng.,9:41-44, 1966.

MERCANTE, E.; SILVA, S.L.; MODOLO, A.J. \& SILVEIRA, J.C.M. Demanda energética e distribuição de sementes de milho em função da velocidade de duas semeadoras. R. Bras. Eng. Agríc. Amb., 9:424-428, 2005.

MIALHE, L.G. Manual de mecanização agrícola. São Paulo, Agronomica Ceres, 1974. p.301.

MIALHE, L.G. Ensaio e certificação de tratores. In: MIALHE, L.G. Máquinas agrícolas: Ensaio \& certificação. Piracicaba, Fundação de Estudos Agrários Luiz de Queiroz, 1996. p.385-462.

OLIVEIRA, M.L. Avaliação do desempenho de uma semeadoraadubadora para plantio direto, em duas classes de solo com diferentes tipos de cobertura vegetal. Viçosa, MG, Universidade Federal de Viçosa, 1997. 50p. (Tese de Mestrado).

SERAUT, A. Lê pneumatique basse pression. CEMAGREF, 50:33-37, 1990. (Bulletin Technique du Machinisme et de l’Équipement Agricole)

SILVA, S.L.; BENEZ, S.H.; RICIERI, R.P. \& PEREIRA, J.O. Demanda energética em sistema de semeadura direta em milho. In: CONGRESSO BRASILEIRO DE ENGENHARIA AGRÍCOLA, 29., Fortaleza, 2000. Anais. Fortaleza, Sociedade Brasileira de Engenharia Agrícola, 2000. CD-ROM.

SILVEIRA, J.C.M.; MODOLO, A.J.; SILVA, S.L. \& GABRIEL FILHO, A. Força de tração e potência de uma semeadora em duas velocidades de deslocamento e duas profundidades de deposição de sementes. R. Bras. Eng. Agríc. Amb., 9:125-128, 2005.

SIQUEIRA, R.; ARAÚJO, A.G.; CASÃO JÚNIOR, R. \& RALISCH, R. Desempenho energético de semeadorasadubadoras de plantio direto na implantação da cultura da soja (Glycine max L.). In: CONGRESSO BRASILEIRO DE ENGENHARIA AGRÍCOLA, 30., Foz do Iguaçu, 2001. Anais. Foz do Iguaçu, Sociedade Brasileira de Engenharia Agrícola, 2001. CD-ROM. 